\title{
openheart Gender-specific secondary prevention? Differential psychosocial risk factors for major cardiovascular events
}

\author{
Christina E Kure, ${ }^{1}$ Yih-Kai Chan, ${ }^{1,2}$ Chantal F Ski, ${ }^{1}$ David R Thompson, ${ }^{1,2}$ \\ Melinda J Carrington, ${ }^{1,2}$ Simon Stewart ${ }^{1,2}$
}

To cite: Kure CE, Chan YK, Ski CF, et al. Gender-specific secondary prevention? Differential psychosocial risk factors for major cardiovascular events. Open Heart 2016;3:e000356. doi:10.1136/openhrt-2015000356

- Additional material is available. To view please visit the journal (http://dx.doi.org/ 10.1136/openhrt-2015000356).

Received 29 October 2015 Revised 8 February 2016 Accepted 15 March 2016

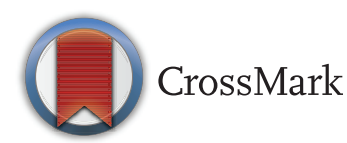

\begin{abstract}
${ }^{1}$ Mary MacKillop Institute for Health Research, Australian Catholic University,

Melbourne, Victoria, Australia ${ }^{2}$ National Health and Medical Research Council of Australia Centre of Research

Excellence to Reduce Inequality in Heart Disease, Melbourne, Victoria, Australia
\end{abstract}

Correspondence to Professor Simon Stewart; Simon.Stewart@acu.edu.au

\section{ABSTRACT}

Objective: To explore the psychosocial determinants and interhospital variability on a major acute cardiovascular event (MACE), during follow-up of a multicenter cohort of patients hospitalised with heart disease, participating in a nurse-led secondary prevention programme.

Methods: Outcome data were retrospectively analysed from 602 cardiac inpatients randomised to postdischarge standard care $(n=296)$, or home-based intervention ( $n=306)$, with prolonged follow-up of individualised multidisciplinary support. Baseline psychosocial profiling comprised depressive status, health-related quality of life (HRQoL), social isolation and mild cognitive impairment (MCl). Multivariate analyses examined the independent correlates of a composite 2-year MACE rate of all-cause mortality and unplanned cardiovascular-related hospitalisation, according to gender.

Results: Participants were aged $70 \pm 10$ years, 431 $(72 \%)$ were men and $377(63 \%)$ had coronary artery disease. During 2-year follow-up, 165 (27\%) participants (114 men, 51 women; $p=0.431$ ) experienced a MACE. Independent correlates of a MACE in men were depressive status (OR 1.95, 95\% $\mathrm{Cl} 1.06$ to $3.58 ; p=0.032$ ), low physical $\mathrm{HRQoL}$ (OR $0.98,95 \% \mathrm{Cl} 0.96$ to $1.00 ; p=0.027$ ) and increasing comorbidity (OR $1.14,95 \% \mathrm{Cl} 1.04$ to 1.25 ; $\mathrm{p}=0.004)$. In women, age (OR $1.06,95 \% \mathrm{Cl} 1.02$ to 1.12; $p=0.008$ ), $\mathrm{MCl}$ (OR 2.38, $95 \% \mathrm{Cl} 1.09$ to 5.18 ; $\mathrm{p}=0.029$ ) and hospital site predicted a MACE (OR 2.32, $95 \% \mathrm{Cl} 1.09$ to 4.93; $\mathrm{p}=0.029$ ).

Conclusions: Psychological determinants, cognitive impairment and responses to secondary prevention are different for men and women with heart disease and appear to modulate cardiovascular-specific outcomes. Early detection of psychosocial factors through routine screening and gender-specific secondary prevention is encouraged.

Trial registration number: 12608000014358.

\section{INTRODUCTION}

It is well established that psychosocial risk factors modulate the development of cardiovascular disease ${ }^{1}$ and can have deleterious effects on outcomes following a cardiac

\section{KEY QUESTIONS}

What is already known about this subject?

- Psychosocial factors (ie, depression and social isolation) increase cardiovascular risk and are associated with adverse prognosis.

What does this study add?

- Psychosocial determinants of, and potential responses to, secondary prevention was markedly different for men and women in a rigorously conducted clinical trial.

How might this impact on clinical practice?

- Early detection of important (and potentially modifiable) psychosocial risk factors via short screening tools should be routinely performed, with a potential need to modulate and apply secondary prevention strategies applied on a gender-specific basis.

event. ${ }^{2}$ There is now a large body of evidence to show that depression, reduced mental and physical health-related quality of life (HRQoL), stress, lack of social support, and cognitive impairment are highly prevalent in cardiac populations. ${ }^{2-8}$ Consequently, adverse prognoses and elevated healthcare usage and costs ensue, potentially due to poor secondary outcomes as a consequence of adherence to suboptimal treatment. ${ }^{9} 10$ While supportive interventions in cardiac patients with depression have been shown to improve mental health, it is unclear if they improve cardiovascular outcomes. ${ }^{10}$

Distinct gender differences in the natural history of cardiac disease and presentation of acute cardiac events is apparent, ${ }^{11}$ with higher rates of depression, asymptomatic presentation and cognitive impairment in women ${ }^{9}$ than in men. ${ }^{8}$ However, few studies have examined the impact of psychosocial risk factors in determining secondary cardiovascular events on a gender-specific basis. ${ }^{2}$ We recently completed the multicenter 
Young @ Heart Study that examined the benefits of a nurse-led, home-based secondary prevention intervention (HBI) in a large cohort of cardiac inpatients (most with coronary artery disease $(\mathrm{CAD})){ }^{7}$ Compared to standard care, patients enrolled in HBI received comprehensive profiling, and an initial report (with recommendations) was sent to their primary care and specialist physician for clinical support and follow-up of any urgent deficits. Our nurse then implemented that plan (explicitly guided by expert secondary prevention guidelines) via a combination of outreached home visits, telephone follow-up, multidisciplinary support and referrals to other allied health professionals (depending on clinic needs). Our most important finding was that HBI resulted in a significant reduction in cardiovascularrelated events; primarily hospitalisations for men. While the findings showed no overall differences between standard care and HBI, the nurse-facilitated HBI was not beneficial for women. All end points emphasised poorer health outcomes relative to standard care in women. ${ }^{7}$ Moreover, hospital site was an independent correlate of cardiac events in women. ${ }^{7}$ We therefore postulated that these findings were mediated by gender differences in psychosocial factors and the response to the patientnurse interaction (as determined by the hospital site).

\section{Study aims and hypotheses}

On the bases of our initial findings, ${ }^{7}$ we conducted a retrospective analysis of the Young @ Heart Study outcomes to examine the potential role of psychosocial factors and hospital site differences in determining a major acute cardiovascular event (MACE), independent of clinical profile. Specifically, it was hypothesised that there would be a differential contribution of psychosocial factors to subsequent MACE rates of all-cause mortality and unplanned cardiovascular-related hospitalisation based on gender. It was further anticipated that gender differentials would arise from a specific response to the study intervention and the nurse-patient interaction (as determined by the hospital recruitment site).

\section{MATERIALS AND METHODS \\ Study population}

The design and primary outcomes of the Young @ Heart Study have been described previously. ${ }^{12}$ Recruited participants were elective and emergency inpatients at two hospitals in Brisbane, Australia; private health insurance holders (Bupa Australia), aged $\geq 45$ years; diagnosed with chronic heart disease (principally $\mathrm{CAD}$, chronic heart failure and arrhythmia (chronic atrial fibrillation)), discharged to home and required long-term management of symptoms and pharmacotherapy. Ethical approval was obtained from each administering hospital's ethics committees, and the study complied with the Declaration of Helsinki and CONSORT guidelines for reporting a pragmatic trial. ${ }^{13}$ All participants gave written informed consent.

\section{Subject profiling}

All participants were comprehensively profiled by the Young@ Heart Study nurses using standardised case report forms and validated assessment tools, ${ }^{12}$ with information gained from a combination of health records and subject interviews.

\section{Postdischarge management}

Participants were randomised (1:1) to receive postdischarge standard care, or the nurse-led standardised HBI programme ${ }^{12}$ delivered by two trained specialist cardiac nurses from two administering hospitals (Hospital-A and Hospital-B). In brief, participants who were randomised to HBI received a comprehensive clinical assessment including an outreach home visit 1-2 weeks postdischarge (baseline), followed by repeat home visits and phone calls (depending on clinic needs) as part of an individualised programme of care (eg, support and appropriate referrals) with a strong focus on preventing progressive cardiac dysfunction to a subsequent MACE.

\section{Psychosocial profile}

The Patient Health Questionnaire-2 (PHQ-2) was used to assess the presence of a depressed mood. ${ }^{14}$ Participants answered either 'yes' or 'no' to detect depressed mood and a loss of interest or pleasure in routine activities. A positive response to either question triggered further testing with the Center for Epidemiologic Studies-Depression Scale $(C E S-D),{ }^{15}$ a reliable self-report questionnaire designed to identify depressive symptomatology from 20 items addressing how the respondent felt or behaved during the previous week. A score $\geq 16$ on the CES-D signifies potential depression. The 12-item short-form health survey was used to assess mental, physical and overall health related quality of life (HRQoL). Using the fivepoint Likert scale, respondents answered each of the 12 subscales measuring eight domains: (1) physical, (2) role physical, (3) bodily pain, (4) general health, (5) vitality, (6) social functioning, (7) emotional role and (8) mental health. ${ }^{16}$ The Montreal Cognitive Assessment (MoCA), was used to identify mild cognitive impairment (MCI) as defined by a score of $<26$ of $30 .{ }^{17}$ Last, assessment of social isolation was determined by household membership (eg, living alone or with others).

\section{Clinical profile}

Extent of each participant's concurrent comorbidity was measured using the Charlson Comorbidity Index adjusted for age. ${ }^{18}$ Demographic profile, clinical profile (heart failure classification, kidney function, triglycerides, blood glucose) and cardiovascular risk factors (smoking habit, alcohol risk, cholesterol, body mass index, diabetes and hypertension), in addition to disease-specific profiling (eg, extent of CAD), were recorded from a standard patient assessment form. 


\section{Major acute cardiovascular events}

As part of the Young @ Heart Study, all hospitalisations were subject to blinded adjudication, and classified according to the discharge summary and principal diagnoses documented by the treating clinician. For the purpose of this study, a MACE was defined as any unplanned/emergency cardiovascular-related hospitalisation, or all-cause mortality, during a 2-year follow-up.

\section{Statistical analyses}

All study analyses were performed retrospectively using SPSS (V.22, SPSS Inc, Chicago, Illinois, USA). Data are presented as mean $( \pm \mathrm{SD})$ and median (IQR) for normally and non-normally distributed continuous variables, respectively. Numbers with percentages in parentheses are reported for categorical variables. Independent samples $\mathrm{t}$ test and Mann-Whitney $\mathrm{U}$ test were used to compare groups on normally and nonnormally distributed continuous variables, respectively. Pearson's $\chi^{2}$ test of independence and OR with 95\% CIs were used to explore categorical variables. Kaplan-Meier survival curves were generated, and a bivariate log-rank test calculated to determine whether there were differences in 2-year MACE (days to first event) according to gender, group randomisation and hospital site. Multivariate logistic regression analyses (backward elimination) were performed to determine the independent predictors of MACE for men and women separately. Independent variables included were baseline psychosocial factor variables, subject demographics, cardiovascular risk factors, concurrent comorbidity and clinical characteristics. Statistical significance was accepted at $\alpha<0.05$ (two-tailed).

\section{RESULTS}

\section{Study cohort}

A total of 602 participants were assessed, of whom 306 (51\%) were randomised to receive the nurse-led HBI. Mean age of participants was $70 \pm 10$ years and majority $(n=431,72 \%)$ were men. CAD $(63 \%)$ was the most common reason for an index event $(71 \%$ underwent a revascularisation procedure), followed by arrhythmia $(20 \%)$ and heart failure (7\%). From a psychosocial perspective, one in five participants (21\%) lived alone, 23\% had potential depressive symptoms (positive PHQ-2), and $28 \%$ had MCI.

\section{Gender profile}

Compared to men, women were significantly older $(73 \pm 10$ vs $68 \pm 9 ; \mathrm{p}<0.0001)$ and less likely to have received a tertiary education ( $23 \%$ vs $44 \%$, OR 0.39 ; CI 0.26 to $0.59 ; \mathrm{p}<0.0001)$. They were also more likely to report potential depressive symptoms (positive PHQ-2: $30 \%$ vs $21 \%$, OR 1.61 , CI 1.07 to $2.40 ; \mathrm{p}=0.020)$, have lower physical HRQoL scores (medium 39 (IQR 38 to $47)$ vs 46 (IQR 37 to 53); $\mathrm{p}<0.0001$ ), and live alone ( $46 \%$ vs $11 \%$, OR 6.5 , CI 4.26 to 9.93 ; $\mathrm{p}<0.0001$ ).

\section{Cardiovascular events}

Overall, 165 patients (27\%), experienced at least one MACE, including 22 (13\%) fatal events, with $33(20 \%)$ and $15(9 \%)$ participants experiencing 2 and $\geq 3$ events, respectively. The overall study flowchart is presented in online supplementary figure A. On average, MACE first occurred at $260 \pm 218$ days post-index hospitalisation. Participants who experienced a MACE were significantly older $(72 \pm 10$ vs $69 \pm 9 ; \mathrm{p}<0.001)$, had more comorbidities (mean Charlson Index 5.7 \pm 2.7 vs 4.5 $\pm 2.3 ; \mathrm{p}=0.001$ ), reduced physical HRQoL score (medium 39 (IQR 31 to $47)$ vs $46(36$ to 53$) ; \mathrm{p}<0.001)$ and were more likely to have MCI ( $38 \%$ vs $25 \%$; $\mathrm{p}=0.002)$.

\section{Gender-specific outcomes}

There were no significant gender differences in the contribution of all-cause deaths or hospitalisations to a MACE (27\% of men vs $30 \%$ of women; $p=0.431$ ). In both women and men, the main reason for rehospitalisation was acute coronary syndrome $(29 \%$ vs $36 \%)$, followed by arrhythmia $(20 \%$ vs $15 \%)$, angina $(18 \%$ vs $15 \%)$, and heart failure (13\% vs $12 \%)$. Of the 114 men and 51 women who had a MACE, women were more likely to suffer from multiple events $(39 \%$ vs $24 \%$, OR 2.08, 95\% CI 1.02 to $4.22 ; \mathrm{p}=0.041$ ).

Table 1 compares event-free status by gender and according to baseline characteristics. On an unadjusted basis, men and women who had experienced a MACE were significantly older, had a greater number of comorbidities and MCI compared with their non-MACE counterparts. For women only, there were differences in MACE rates according to the enrolling hospital (and by implication, the healthcare team applying the study intervention) with a greater proportion of women from Hospital-B who had a MACE (38\% vs $19 \%$; $\mathrm{p}=0.006$ ). Alternatively, in men only, potential depressive symptoms were associated with a higher MACE rate $(p=0.005)$.

Table 2 displays multivariate variables predicting a MACE using logistic regression (backward elimination procedure). Independent correlates of a 2-year MACE, overall, were higher Chalrson comorbidity, reduced physical HRQoL and MCI (table 2). When examining men and women separately, greater comorbidity, low physical HRQoL and depressive status (positive PHQ-2 plus CES-D score $\geq 16$ ) were independently associated with an increased risk of a 2-year MACE in men (table 2). Conversely, in women, age, MCI at baseline and Hospital-B were associated with an equivalent increased risk.

\section{Group management and gender outcomes}

Overall, there was no difference in 2-year MACE according to group randomisation $(82(28 \%)$ standard care versus 83 (27\%) HBI; $\mathrm{p}=0.874)$. However, genderspecific differences were found in the HBI group with proportionally more women than men experiencing a MACE during study follow-up (35\% vs $24 \%$, log-rank $\left.\chi^{2}=4.5 ; \mathrm{p}=0.034\right)$. Alternatively, there were no differences 
Table 1 Baseline characteristics of participants who had an event, or were event-free, in the entire cohort and according to gender

\begin{tabular}{|c|c|c|c|c|c|c|c|c|c|c|}
\hline \multirow[b]{2}{*}{ Characteristic } & \multicolumn{4}{|l|}{ All $(\mathrm{N}=602)$} & \multicolumn{3}{|l|}{ Men $(\mathrm{N}=431)$} & \multicolumn{3}{|c|}{ Women $(\mathrm{N}=171)$} \\
\hline & Total & $\begin{array}{l}\text { Event-free } \\
(\mathrm{N}=437)\end{array}$ & $\begin{array}{l}\text { Event } \\
(\mathrm{N}=165)\end{array}$ & p Value & $\begin{array}{l}\text { Event-free } \\
(\mathrm{N}=317)\end{array}$ & $\begin{array}{l}\text { Event } \\
(\mathrm{N}=114)\end{array}$ & p Value & $\begin{array}{l}\text { Event-free } \\
(\mathrm{N}=120)\end{array}$ & $\begin{array}{l}\text { Event } \\
(\mathrm{N}=51)\end{array}$ & p Value \\
\hline \multicolumn{11}{|l|}{ Demographic profile } \\
\hline Age (years) & $70 \pm 10$ & $69 \pm 9$ & $72 \pm 10$ & $<0.001$ & $68 \pm 9$ & $70 \pm 10$ & 0.033 & $71 \pm 10$ & $77 \pm 8$ & $<0.001$ \\
\hline Education $>12$ years (\%) & $228(38)$ & $176(40)$ & $52(32)$ & 0.051 & $145(46)$ & $43(38)$ & 0.150 & $31(26)$ & $9(18)$ & 0.247 \\
\hline Study site & & & & 0.073 & & & 0.713 & & & 0.006 \\
\hline Hospital A (\%) & $258(43)$ & $197(76)$ & $61(24)$ & & $137(74)$ & $47(26)$ & & $60(81)$ & $14(19)$ & \\
\hline Hospital B (\%) & $344(57)$ & $240(70)$ & $104(30)$ & & $180(73)$ & $67(27)$ & & $60(62)$ & $37(38)$ & \\
\hline Group randomisation & & & & 0.874 & & & 0.200 & & & 0.104 \\
\hline $\mathrm{HBI}(\%)$ & $306(51)$ & $223(73)$ & $83(27)$ & & $164(76)$ & $51(24)$ & & $59(65)$ & $32(35)$ & \\
\hline Standard care (\%) & $296(46)$ & $214(72)$ & $82(28)$ & & $153(71)$ & $63(29)$ & & $61(76)$ & $19(24)$ & \\
\hline \multicolumn{11}{|l|}{ Risk factor profile } \\
\hline $\mathrm{BMI}>25 \mathrm{~kg} / \mathrm{m}^{2}(\%)^{*}$ & $357(68)$ & $265(68)$ & $92(66)$ & 0.549 & $201(72)$ & $67(69)$ & 0.544 & $64(59)$ & $25(58)$ & 0.948 \\
\hline Total cholesterol (mmol/L) & $3.9 \pm 1.1$ & $3.9 \pm 1.1$ & $3.9 \pm 1.1$ & 0.784 & $3.8 \pm 1.1$ & $3.7 \pm 1.0$ & 0.377 & $4.1 \pm 1.5$ & $4.3 \pm 1.0$ & 0.488 \\
\hline Systolic BP (mm Hg) & $139 \pm 23$ & $139 \pm 23$ & $140 \pm 25$ & 0.530 & $138 \pm 23$ & $138 \pm 24$ & 0.971 & $143 \pm 23$ & $147 \pm 25$ & 0.374 \\
\hline Diastolic BP (mm Hg) & $75 \pm 12$ & $75 \pm 11$ & $73 \pm 14$ & 0.072 & $76 \pm 11$ & $74 \pm 13$ & 0.176 & $73 \pm 12$ & $71 \pm 15$ & 0.294 \\
\hline Type II diabetes (\%) & $125(21)$ & $83(19)$ & $42(26)$ & 0.081 & $63(20)$ & $27(24)$ & 0.391 & $20(17)$ & $15(29)$ & 0.059 \\
\hline Blood glucose $(\mathrm{mmol} / \mathrm{L})$ & $5.8(5.2-6.8)$ & $5.8(5.2-6.8)$ & $5.9(5.2-7.0)$ & 0.187 & $5.8(5.2-6.8)$ & $5.9(5.2-6.9)$ & 0.676 & $5.7(5.1-6.4)$ & $5.9(5.2-7.8)$ & 0.079 \\
\hline Current smoker (\%) & $52(9)$ & $41(9)$ & $11(7)$ & 0.299 & $31(10)$ & $11(10)$ & 0.989 & $10(8)$ & 0 & 0.034 \\
\hline High alcohol risk (\%) & $114(19)$ & $90(21)$ & $24(15)$ & 0.097 & $86(27)$ & $24(21)$ & 0.218 & $4(3)$ & 0 & 0.187 \\
\hline \multicolumn{11}{|l|}{ Clinical presentation } \\
\hline Charlson comorbidity ${ }^{18}$ & $4.9 \pm 2.5$ & $4.5 \pm 2.3$ & $5.7 \pm 2.7$ & $<0.001$ & $4.4 \pm 2.3$ & $5.4 \pm 2.6$ & $<0.001$ & $4.8 \pm 2.2$ & $6.3 \pm 2.7$ & $<0.001$ \\
\hline eGFR<60 mL/min/1.73 $\mathrm{m}^{2}(\%) \dagger$ & $103(22)$ & $58(17)$ & $45(35)$ & $<0.001$ & $35(14)$ & $28(31)$ & $<0.001$ & $23(26)$ & $17(43)$ & 0.053 \\
\hline \multicolumn{11}{|c|}{ Functional status } \\
\hline NYHA class II, III, VI (\%) & $280(47)$ & $189(43)$ & $91(56)$ & 0.006 & $126(40)$ & $57(51)$ & 0.036 & $63(53)$ & $34(67)$ & 0.098 \\
\hline Canadian class II, III, VI (\%) & $225(38)$ & $158(36)$ & $67(42)$ & 0.244 & $107(34)$ & $49(45)$ & 0.048 & $51(43)$ & $18(35)$ & 0.357 \\
\hline 6 min walk test $(\mathrm{m}) \ddagger$ & $305 \pm 119$ & $312 \pm 116$ & $285 \pm 126$ & 0.024 & $328 \pm 111$ & $309 \pm 117$ & 0.158 & $268 \pm 115$ & $226 \pm 127$ & 0.065 \\
\hline \multicolumn{11}{|l|}{ Primary diagnosis } \\
\hline Arrhythmia (\%) & $119(20)$ & $80(67)$ & $39(33)$ & & $57(18)$ & $25(22)$ & & $23(19)$ & $14(27)$ & \\
\hline CAD (\%) & 377 (63) & $289(66)$ & $88(53)$ & & $220(70)$ & $65(57)$ & & $69(58)$ & $23(45)$ & \\
\hline Heart failure (\%) & $45(7)$ & $33(8)$ & $12(7)$ & & $14(4)$ & $7(6)$ & & $19(16)$ & $5(10)$ & \\
\hline PAD (\%) & $1(0.2)$ & $1(0.2)$ & 0 & & $1(0.2)$ & 0 & & 0 & 0 & \\
\hline Renal disease (\%) & $5(0.8)$ & $1(0.2)$ & $4(2)$ & & 0 & $2(2)$ & & $1(1)$ & $2(4)$ & \\
\hline Valve disease (\%) & $17(3)$ & $10(2)$ & $7(4)$ & & $9(3)$ & $5(4)$ & & $1(1)$ & $2(4)$ & \\
\hline Other (\%) & $37(6)$ & $22(5)$ & $15(9)$ & & $15(5)$ & $10(9)$ & & $7(6)$ & $5(10)$ & \\
\hline \multicolumn{11}{|l|}{ Psychosocial factors } \\
\hline Patient lives alone (\%) & $127(21)$ & $86(20)$ & $41(25)$ & 0.144 & $36(11)$ & $13(12)$ & 0.943 & $50(42)$ & $28(55)$ & 0.112 \\
\hline \multicolumn{11}{|l|}{ Quality of life§ } \\
\hline SF-12 Physical & $43(34-52)$ & $46(36-53)$ & $39(31-47)$ & $<0.001$ & $47(38-53)$ & $41(33-49)$ & 0.001 & $40(30-48)$ & $34(26-44)$ & 0.080 \\
\hline SF-12 Mental & $55(48-59)$ & $55(48-59)$ & $26(24-28)$ & 0.274 & $56(49-60)$ & $54(47-60)$ & 0.333 & $54(48-59)$ & $54(46-58)$ & 0.757 \\
\hline
\end{tabular}

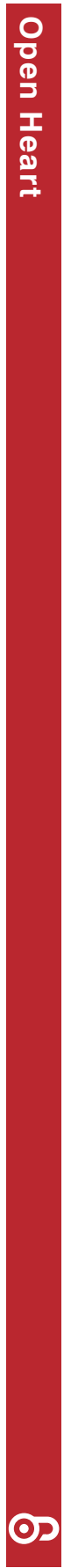




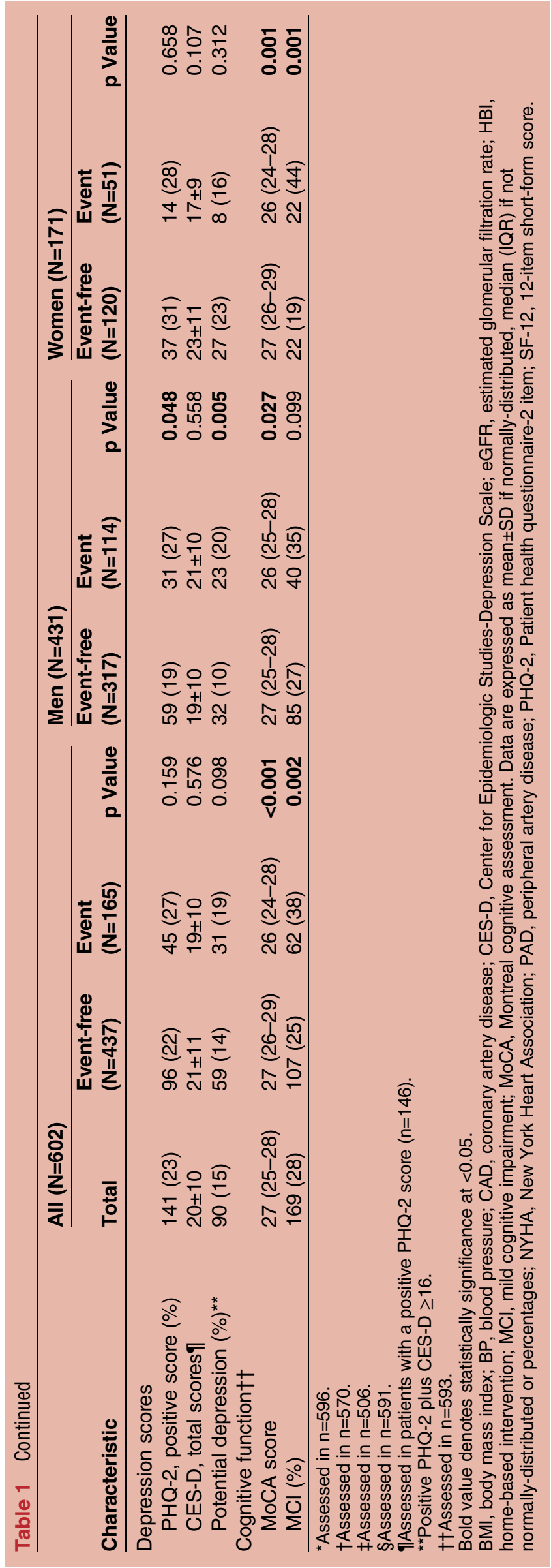

Table 2 Multivariate logistic regression models of predictors of a 2-year MACE in all patients and according to gender

\begin{tabular}{|c|c|c|}
\hline Predictor & OR $(95 \% \mathrm{Cl})$ & $\bar{p}$ Value \\
\hline \multicolumn{3}{|l|}{ All patients $(n=546)$} \\
\hline $\begin{array}{l}\text { Charlson comorbidity } \\
\text { index }\end{array}$ & 1.15 (1.06 to 1.25$)$ & 0.001 \\
\hline SF-12 physical score & $0.98(0.96$ to 1.00$)$ & 0.020 \\
\hline Mild cognitive impairment & 1.53 (1.02 to 2.30$)$ & 0.040 \\
\hline \multicolumn{3}{|c|}{ Men $(n=402)$} \\
\hline $\begin{array}{l}\text { Charlson comorbidity } \\
\text { index }\end{array}$ & $1.14(1.04$ to 1.25$)$ & 0.004 \\
\hline SF-12 physical score & $0.98(0.96$ to 1.00$)$ & 0.030 \\
\hline Potential depression* & 1.95 (1.06 to 3.58$)$ & 0.030 \\
\hline \multicolumn{3}{|l|}{ Women $(n=162)$} \\
\hline Age & 1.06 (1.02 to 1.12$)$ & 0.008 \\
\hline Mild cognitive impairment & 2.38 (1.09 to 5.18$)$ & 0.030 \\
\hline Study-site (hospital-B) & 2.32 (1.09 to 4.93$)$ & 0.030 \\
\hline
\end{tabular}

for those randomised to standard care according to gender $(24 \%$ vs $29 \%$; $\mathrm{p}=0.313)$.

\section{Group management by study-site by gender outcomes}

There were notable differences in the overall pattern of 2-year MACE according to hospital site (24\% from Hospital-A vs $30 \%$ from Hospital-B), however, it was not statistically significant $(p=0.073)$. Proportionately, more women than men from Hospital-B experienced a MACE, although this was of borderline significance $\left(38 \%\right.$ vs $27 \%$, log-rank $\left.\chi^{2}=3.8, p=0.052\right)$. Further, significantly more women from Hospital-A in the standard care group experienced a MACE (33\% vs $12 \%$; $\mathrm{p}=0.028$ ). There was a similar (not significant) trend in women receiving HBI ( $43 \%$ vs $25 \%$; $\mathrm{p}=0.064$; figure $1 \mathrm{~A}$ ) and no significant differences in men (HBI, $\mathrm{p}=0.553$; standard care, $\mathrm{p}=0.888$; figure $1 \mathrm{~B}$ ).

Figure 2 shows the log-rank survival curves in Hospital-A and Hospital-B according to gender and group randomisation. The 2-year MACE rate for participants receiving HBI was similar for women and men enrolled from Hospital-A (22\% vs $25 \%$ ), although there was a significantly higher 2-year MACE rate in men only (29\% vs $12 \%, \mathrm{p}=0.045$; figure $2 \mathrm{~A}$ ). For participants receiving standard care, there were no significant gender differences observed for Hospital-B $(p=0.761)$. However, in contrast with Hospital-A, there was a significantly higher 2-year MACE rate in women than men in subjects at Hospital-B (43\% vs 25\%; figure 2B).

\section{DISCUSSION}

We undertook a post hoc analysis of a nurse-led secondary prevention program ${ }^{7}$ to determine the impact of psychosocial factors and/or hospital site on 2-year MACE according to gender. Overall, we found that 

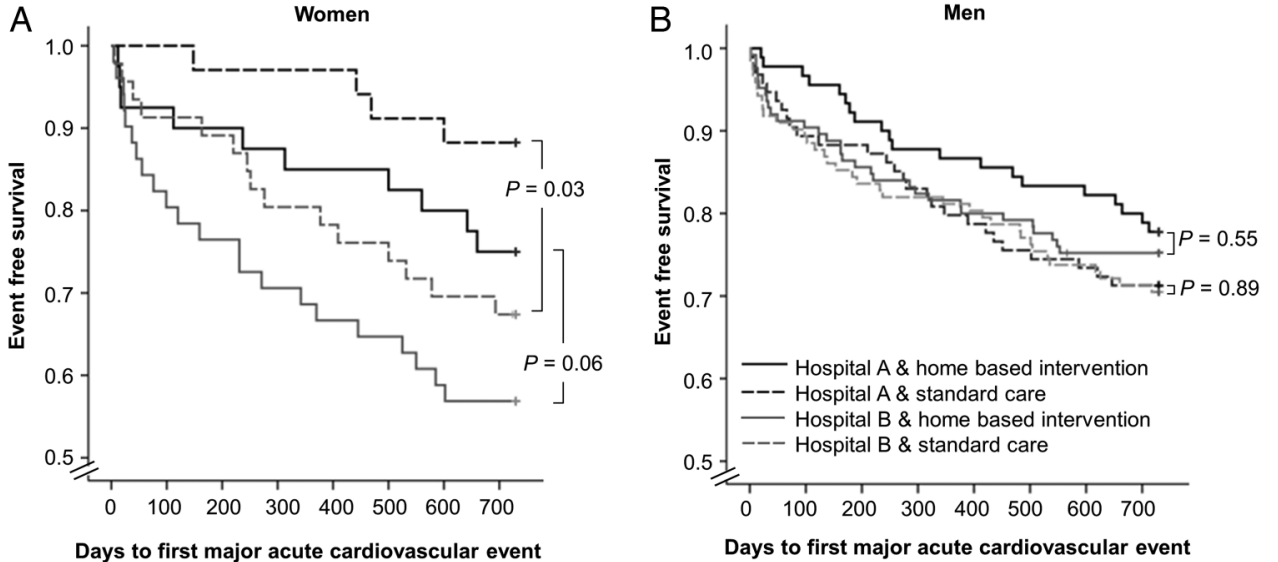

Figure 1 Kaplan-Meier event-free survival from a major acute cardiovascular event in women (A) and men (B), according to group randomisation and hospital enrolment.

more women than men experienced a MACE. Increasing comorbidity, reduced physical HRQoL and MCI independently predicted a 2-year MACE. In men only, independent correlates of a MACE were reduced physical HRQoL, increasing comorbidity and depressive status, whereas independent correlates for women were hospital site, older age and MCI. We found a markedly different response to the HBI in women from one recruitment hospital only. These findings suggest that, independent of clinical profile, different psychosocial factors contribute to a 2-year MACE in men and women exposed to a secondary prevention programme for cardiovascular disease. Additionally, patient-nurse interaction, particularly in women, may influence the way patients respond to the programme delivered in the home.

Findings from the current study support the hypothesis that in a sample of predominantly CAD patients, psychosocial factors can differentially influence secondary cardiovascular outcomes in men and women. Our findings also agree with previous research to show that those cardiac patients with psychosocial risk factors including depressive symptoms, ${ }^{34}$ reduced physical but not mental HRQoL, ${ }^{5}$ and impaired cognitive function ${ }^{8}{ }^{19}$ have poorer outcomes and greater mortality risk. Moreover, we have further demonstrated gender-specific psychosocial risk factors. The finding that women, overall, who had a 2-year MACE, were more likely to have MCI, is congruent with previous research demonstrating that MCI predicts health outcomes and mortality. ${ }^{8} 19$ This may be explained by a limited ability to comprehend and adhere to medical treatments as a result of greater cognitive impairement. ${ }^{8}$ It is possible that MCI as a predictor of a 2-year MACE in women may have been influenced by a combination of factors including old age, more likely to be living alone and depressed, which is common among cardiac patients with MCI. ${ }^{9}$

As with previous studies, we found more depressive symptoms in women than men; ${ }^{9}{ }^{20}$ however, men with depressive symptoms were almost twice more likely to have a MACE. It is possible that men with depressive symptoms in our study benefited from the additional support provided in HBI leading to improved mood, lower inflammation ${ }^{21}$ and fewer adverse events. Moreover, the finding that reduced physical, but not mental HRQoL also predicted a MACE in men supports earlier studies in cardiac patients. ${ }^{5}$ It is possible that the
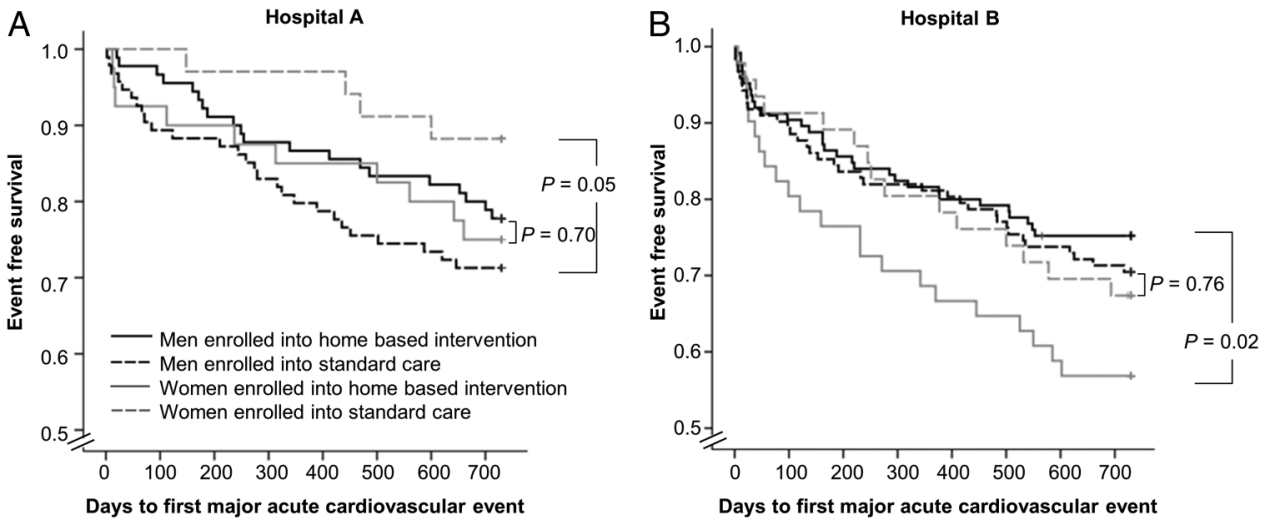

Figure 2 Kaplan-Meier event-free survival from a major acute cardiovascular event in patients recruited from Hospitals $A$ (A) and $\mathrm{B}(\mathrm{B})$, according to group randomisation and gender. 
contributing factors of a MACE for men might be psychological, since depressed cardiac patients were more likely to report worse physical HRQoL than non-depressed patients, ${ }^{22}$ and as observed in men in our current study. Contrary to previous studies, ${ }^{2}{ }^{23}$ social isolation did not predict a 2-year MACE according to gender, suggesting that social isolation is a non-gender-specific predictor of a secondary cardiac event. ${ }^{27}$

We found that the patient-nurse interaction, as reflected by hospital site, predicted a 2-year MACE. The finding that women did not acquire the same benefit at one hospital, even after adjusting for clinical characteristics and psychosocial factors, further supports our initial findings. ${ }^{7}$ Differential outcomes were seen between hospital sites, despite controlling for treatment fidelity by conducting intensive, standardised, prestudy and ongoing training for the two cardiac nurses who delivered the HBI programme at respective hospitals. One explanation may be due to confounding factors impacting beyond intervention fidelity (eg, personality, beliefs, attitudes) of trained personnel delivering the intervention. Moreover, unequal patient numbers (130 patients in Hospital-A vs 176 patients in Hospital-B) might cause an unbalanced/overwhelming caseload management for Hospital-B. Recruitment of additional nurses in future studies, especially for busier sites, may alleviate the potentially high work load on these nurses. Taken together, our findings support earlier work demonstrating that women may respond differently than men to $\mathrm{HBI}^{24}$

These observations are important as they present a need to re-evaluate current secondary prevention programmes by addressing gender differences in psychosocial and cognitive factors associated with increased risk of future cardiac events. Through prompt intervention to eliminate/reduce the psychosocial risks (particularly depression and diminished physical HRQoL in men) and cognitive impairment (especially for women) detected via routine screening using brief measures as per HBI, there is potential to prevent adverse health outcomes in cardiac patients. Future studies are required to test this hypothesis. Collectively, these findings support a collaborative care approach where appropriate referral can be initiated when necessary, linking patients with cardiovascular and mental health clinicians so that patients at risk of MACEs can receive early intervention of tailored, gender-specific, integrated treatments and lifestyle modifications. ${ }^{6}{ }^{20}$ One unique aspect of nurse-led programmes is not only recommended routine screening for depression following a cardiac event ${ }^{25}{ }^{26}$ but also other pertinent psychosocial risk factors including HRQoL, social isolation, and cognitive impairment.

Nurse-led, multidisciplinary, home-based disease management programmes have shown to improve recovery and reduce hospitalisations in cardiac patients, ${ }^{27} 28$ principally in men but not women. ${ }^{7}$ However, evidence for the way in which psychosocial risk factors modulate how patients respond to secondary prevention programmes, especially for gender, are limited. ${ }^{2}$ Our study has attempted to address this issue by providing a greater understanding of the differential gender effects of nurse-led HBIs. Consequently, our findings reinforce the need for a 'patient-centred' approach to secondary prevention $^{29}$ with a major consideration of the potentially different needs of men and women. Simultaneously, they are a timely reminder of 'operator dependence' in applying complex disease-management interventions with the potential to trigger a 'clinical cascade' that can provoke more hospital activity. ${ }^{30}$ However, this is a hypothetical construct and needs to be tested in future studies. Additionally, over-reporting by women who may be more attentive to their symptoms, and possible under-reporting by men may explain the gender differences. Furthermore, anxiety and stress, especially job-related stressors, are factors related to poor health outcomes, ${ }^{2}{ }^{9}$ however, we did not measure these, so future studies exploring these possible links are warranted. Future research exploring cardiac management programmes that are gender-specific and tailored to the individual, by way of addressing psychosocial risk using brief screening measures to profile patients, and factors influencing patient compliance such as the response to personalised care are urgently required.

A number of limitations influence the cautious interpretation of these data. First, this was a post hoc analysis, and we did not prospectively profile patients from a psychosocial perspective in anticipation of the initial findings. Additionally, the selective choice of only two hospitals and recruitment of privately insured patients who are likely to have higher education and income levels may bias results. The cohort tested were predominantly patients hospitalised with CAD, however, a sensitivity analysis indicated there were no differences in the outcomes seen in the pooled cohort. Furthermore, we acknowledge the risk of multiple testing and the risk of type I error, and future studies are therefore needed to replicate our results. Additionally, secondary prevention medication adherence was not accounted for as possible predictors, which may have influenced event rates. Finally, with the analyses being exploratory, results from this trial need to be confirmed in larger hypothesisdriven clinical studies.

\section{CONCLUSION}

These data, from a large nurse-led, multidisciplinary, secondary prevention programme further support the hypothesis that the psychosocial profile of acute cardiac patients who experience a MACE differs between men and women. Notably, overall depressive status and physical HRQoL was a significant predictor of a MACE in men, and MCI and administering hospital in women. This study has demonstrated that screening cardiac patients according to psychosocial risk and ongoing monitoring can predict poor health outcomes. Also, who delivers the intervention is another important 
factor as this will have an impact on how the patient benefits from the intervention. Future research exploring cardiac management programmes that are tailored to such profiling, particularly on a gender-specific basis, given an apparently differential response to more personalised care, are required. Finally, these data have important implications for the delivery of such care, to ensure intervention fidelity, and that secondary prevention is appropriately tailored to the patient according to individual responses to this care.

Acknowledgements The authors acknowledge the dedicated research teams at the Wesley Hospital and St Andrews War Memorial Hospital for their support with patient recruitment, data collection and study administration.

Contributors MJC and SS contributed to the study concept and design. Y-KC and MJC were responsible for data coordination and management. CEK, Y-KC and SS were responsible for statistical analysis of the data. CEK was responsible for drafting of the initial manuscript. All authors contributed to interpretation of the data, drafting and reviewing of the manuscript.

Funding The Young @ Heart Study was funded by Bupa Australia and Bupa Health Foundation. MJC (1032934) and SS (1041796) are supported by the National Health and Medical Research Council of Australia.

Competing interests None declared.

Patient consent Obtained

Ethics approval This study had approval from the UnitingCare Health Human Research Ethics Committee (approval \#200773).

Provenance and peer review Not commissioned; externally peer reviewed.

Data sharing statement No additional data are available.

Open Access This is an Open Access article distributed in accordance with the Creative Commons Attribution Non Commercial (CC BY-NC 4.0) license, which permits others to distribute, remix, adapt, build upon this work noncommercially, and license their derivative works on different terms, provided the original work is properly cited and the use is non-commercial. See: http:// creativecommons.org/licenses/by-nc/4.0/

\section{REFERENCES}

1. Rozanski A, Blumenthal JA, Davidson KW, et al. The epidemiology, pathophysiology, and management of psychosocial risk factors in cardiac practice: the emerging field of behavioral cardiology. J Am Coll Cardiol 2005;45:637-51.

2. Glozier N, Tofler GH, Colquhoun DM, et al. Psychosocial risk factors for coronary heart disease. Med J Aust 2013;199:179-80.

3. Barth J, Schumacher M, Herrmann-Lingen C. Depression as a risk factor for mortality in patients with coronary heart disease: a meta-analysis. Psychosom Med 2004;66:802-13.

4. Meijer A, Conradi HJ, Bos EH, et al. Prognostic association of depression following myocardial infarction with mortality and cardiovascular events: a meta-analysis of 25 years of research. Gen Hosp Psychiatry 2011;33:203-16.

5. Rumsfeld JS, MaWhinney S, McCarthy M Jr, et al. Health-related quality of life as a predictor of mortality following coronary artery bypass graft surgery. JAMA 1999;281:1298-303.

6. Ski CF, Page K, Thompson DR, et al. Clinical outcomes associated with screening and referral for depression in an acute cardiac ward. $J$ Clin Nurs 2012;21:2228-34.

7. Carrington MJ, Chan YK, Calderone A, et al. A multicenter, randomized trial of a nurse-led, home-based intervention for optimal secondary cardiac prevention suggests some benefits for men but not for women: the Young at Heart Study. Circ Cardiovasc Qual Outcomes 2013;6:379-89.

8. McLennan SN, Pearson SA, Cameron J, et al. Prognostic importance of cognitive impairment in chronic heart failure patients: does specialist management make a difference? Eur $J$ Heart Fail 2006;8:494-501.

9. Pająk A, Jankowski $P$, Kotseva $K$, et al. Depression, anxiety, and risk factor control in patients after hospitalization for coronary heart disease: the EUROASPIRE III Study. Eur J Prev Cardiol 2013;20:331-40.

10. Turner A, Murphy BM, Higgins RO, et al. An integrated secondary prevention group programme reduces depression in cardiac patients. Eur J Prev Cardiol 2014;21:153-62.

11. Milner KA, Funk M, Richards S, et al. Gender differences in symptom presentation associated with coronary heart disease. Am J Cardiol 1999;84:396-9.

12. Chan YK, Stewart S, Calderone A, et al. Exploring the potential to remain "Young @ Heart": Initial findings of a multi-centre, randomized study of nurse-led, home-based intervention in a hybrid health care system. Int J Cardiol 2012;154:52-8.

13. Antes G. The new CONSORT statement. BMJ 2010;340:c1432.

14. Arroll B, Khin N, Kerse N. Screening for depression in primary care with two verbally asked questions: Cross sectional study. BMJ 2003;327:1144-6.

15. Radloff LS. The CES-D scale: a self-report depression scale for research in the general population. Appl Psychol Meas 1977:1:385-401.

16. Ware JE Jr, Kosinski M, Keller SD. A 12-Item Short-Form Health Survey: construction of scales and preliminary tests of reliability and validity. Med Care 1996;34:220-33.

17. Nasreddine ZS, Phillips NA, Bédirian V, et al. The Montreal Cognitive Assessment, MoCA: A brief screening tool for mild cognitive impairment. J Am Geriatr Soc 2005;53:695-9.

18. Charlson ME, Pompei P, Ales KA, et al. A new method of classifying prognostic comorbidity in longitudinal studies: development and validation. J Chronic Dis 1987;40:373-83.

19. O'Donnell M, Teo K, Gao P, et al. Cognitive impairment and risk of cardiovascular events and mortality. Eur Heart J 2012;33: 1777-86.

20. McGrady A, McGinnis R, Badenhop D, et al. Effects of depression and anxiety on adherence to cardiac rehabilitation. $J$ Cardiopul Rehabil Prev 2009;29:358-64.

21. Frasure-Smith N, Lespérance F, Irwin MR, et al. Depression, C-reactive protein and two-year major adverse cardiac events in men after acute coronary syndromes. Biol Psychiatry 2007:62:302-8.

22. Gottlieb SS, Khatta M, Friedmann E, et al. The influence of age, gender, and race on the prevalence of depression in heart failure patients. J Am Coll Cardiol 2004;43:1542-9.

23. Brummett BH, Barefoot JC, Siegler IC, et al. Characteristics of socially isolated patients with coronary artery disease who are at elevated risk for mortality. Psychosom Med 2001;63: 267-72.

24. Frasure-Smith $\mathrm{N}$, Lespérance $\mathrm{F}$, Prince $\mathrm{RH}$, et al. Randomised trial of home-based psychosocial nursing intervention for patients recovering from myocardial infarction. Lancet 1997;350:473-9.

25. Lichtman JH, Bigger JTJr, Blumenthal JA, et al. Depression and coronary heart disease: recommendations for screening, referral, and treatment: a science advisory from the American Heart Association Prevention Committee of the Council on Cardiovascular Nursing, Council on Clinical Cardiology, Council on Epidemiology and Prevention, and Interdisciplinary Council on Quality of Care and Outcomes Research: endorsed by the American Psychiatric Association. Circulation 2008:118:1768-75.

26. Colquhoun DM, Bunker SJ, Clarke DM, et al. Screening, referral and treatment for depression in patients with coronary heart disease. Med JAust 2013;198:1-7.

27. Pearson S, Inglis SC, McLennan SN, et al. Prolonged effects of a home-based intervention in patients with chronic illness. Arch Intern Med 2006;166:645-50.

28. Stewart S, Horowitz JD. Home-based intervention in congestive heart failure: long-term implications on readmission and survival. Circulation 2002;105:2861-6.

29. Redfern J, Briffa T, Ellis E, et al. Choice of secondary prevention improves risk factors after acute coronary syndrome: 1-year follow-up of the CHOICE (Choice of Health Options in prevention of Cardiovascular Events) randomized controlled trial. Heart 2009:95:468-75.

30. Mold JW, Stein HF. The cascade effect in the clinical care of patients. N Engl J Med 1986;314:512-14. 